\title{
Ethics as a Game? Towards a Framework for Game Design
}

\author{
Yuan Yuan' ${ }^{1}$ Kun Fu' ${ }^{2}$, Barend Pieter Venter ${ }^{*}$, Thomas Hainey ${ }^{3}$ \\ ${ }^{1}$ Division of Culture and Creativity, Beijing Normal University-Hong Kong Baptist University United International College, \\ Zhuhai, China \\ ${ }^{2}$ Digital Media Art Department, Xiamen Academy of Arts and Design, Fuzhou University, Xiamen, China \\ ${ }^{3}$ School of Engineering and Computing, University of the West of Scotland, Paisley, UK \\ Email: ^ben-piet@hotmail.com
}

How to cite this paper: Yuan, Y., Fu, K. Venter, B. P., \& Hainey, T. (2019). Ethics as a Game? Towards a Framework for Game Design. Sociology Mind, 9, 135-150. https://doi.org/10.4236/sm.2019.93010

Received: April 23, 2019

Accepted: May 18, 2019

Published: May 21, 2019

Copyright (c) 2019 by author(s) and Scientific Research Publishing Inc. This work is licensed under the Creative Commons Attribution International License (CC BY 4.0).

http://creativecommons.org/licenses/by/4.0/

\begin{abstract}
Citizen morality reflects civilization and is significant to society. Ethics education for improving morality, especially in China, may fail because of its reliance on lecture-based teaching. Game-based learning presents an innovative approach to ethics education. This paper identifies problems in tertiary ethics education and reviews relevant game design principles before establishing a framework for designing educational games that may assist in ethics education. It then proposes a game design model for teaching ethics.
\end{abstract}

\section{Keywords}

Games for Learning, Framework, Ethics Teaching, Pedagogy, Game Design

\section{Introduction}

Even though China's economy is developing rapidly, its social systems are still relatively lagging behind. Social problems are increasing, in many cases driven by narrow individual interests such as greed. As such, China is facing growing challenges in dealing with social ethical issues, and is facing a situation whereby it begins to suffer costs in terms of its social and economic spheres (Shang, Liu, \& Cao, 2019). Since universities and colleges present ideal opportunities for teaching ethics, it is necessary to enhance ethics education at the tertiary level, since students are on the threshold of stepping into society, where they will be required to make ethical decisions. Should they lack moral sensitivity, students may lose their faith in morality, ending up with distorted values and even confused ambitions. These will not only impact negatively on their lives, but also on 
society at large. There is, therefore, a need for tertiary educational institutions to integrate ethics into their study plans and syllabi. Martinkovičová \& Benčiková (2017) show the need for this based on their argument that the professional world requires students with ethical competences.

Through observing the model of moral and ethical courses, it was found that the mode of teaching ethics courses is still very much based on the lecturer-centred mode of delivery. This linear educational mode basically teaches students about ethical concepts and explains them in certain contexts. However, it lacks reflective and dynamic thinking in a practical setting. Notwithstanding this, some lecturers endeavour to enrich class activities by adopting diverse methods, including case analysis (Kalaitzidis \& Schmitz, 2012), group discussion (Dinc \& Görgülü, 2002), and role play (Gropelli, 2010; Tuxbury, McCauley, \& Lement, 2012; Vanlaere, Coucke, \& Gastmans, 2010) to improve students' understanding of ethical concepts and moral decisions. Through situational analysis, students learn how to make decisions when facing ethical dilemmas. However, the lecturer-centred teaching mode cannot fully satisfy students who grew up in an advanced technological and entertaining environment.

\section{Methodology}

In order to establish the attitudes of students towards the lecturer-centred teaching mode, the authors conducted a pilot study among college students, as well as their teachers, to investigate their perceived attitudes towards an existing ethics course using mainly lectures as its pedagogical approach. The course is entitled "Applied Ethics".

\subsection{Students}

A total of 88 students, who have completed this course, were recruited to participate in this study by means of a purposive sampling method between November and December 2018. The college is small and only has two cohorts of students with small-size classes. In the end, 63 valid questionnaires were returned. The 13-question survey included five questions on individual experiences in lecture-based teaching settings and asked respondents to self-report on perceived advantages and disadvantages of lecture-based teaching approaches as well as their expectations of game-based learning. In addition, other questions probed general information about academic background, duration of playing games, and media preferences for receiving education material about ethics.

\subsection{Lecturers}

The research team also conducted half hour to one-hour-long qualitative interviews with the two lecturers who teach ethics in the same college. The interview questions included questions focusing on their experience regarding the teaching of ethics. Interviews were conducted and recorded via Skype. 


\section{Results}

The results of these investigations were interesting, to say the least. Notwithstanding criticism against it as discussed earlier, the lecture-based teaching mode has its positive aspects. A summary of some responses is provided in Table 1.

When discussing the game-based learning approach, respondents had a variety of opinions. They felt that this approach would be interesting and vivid, and that they would be more involved in learning, while learning more from playing games. On the whole, they felt that games would help them absorb knowledge during play, and that its high degree of participation would enhance their understanding and memory. Indeed, it would be easier to focus on learning while playing games, and that time will fly, since they will be more motivated. In sum, respondents felt that learning in a good and happy mood will improve their learning efficiency, and that games would stimulate their curiosity and encourage learning.

It seems that students and lecturers hold similar opinions regarding the different teaching approaches and their effects. Lecturers acknowledged, based on the self-reporting from respondents, that there are problems with the lecturer-centred approach, and that there is still space to improve existing teaching approaches for this particular ethics course. The positive opinions held by students regarding game-based learning are supported by the lecturers who teach the ethics course at the selected college. They noted that, in particular, students who are exposed to "exciting" practical subjects such as 3D Animation, Interactive Design, Drawing, and Painting (to name a few) will find it hard to be stimulated by having to learn theory-oriented courses (such as ethics). Even though the lecturers tried to enrich their teaching approaches, they strongly welcome a supplementary approach which could generate higher levels of motivation in learning ethics.

Interestingly, no matter whether at business schools, medical schools, finance departments, or schools of media and communication, computer-based educational programs have long been used on a large scale to teach discipline-specific skills, for example finance and cashier software. These kinds of software have been very successful in training individual capabilities by replicating real-world professional practice. Just as interestingly, computer programs are seldom (if ever) employed to cultivate philosophical skills such as ethical sensitivity, thinking about issues from divergent viewpoints, resolving ethical conflicts and other similar "soft" skills. Most certainly, computer games have not yet entered this realm.

Table 1. Summary of responses.

\begin{tabular}{ll}
\hline Advantages of lecture-centric delivery & Disadvantages of lecture-centric delivery \\
\hline - Provides clear learning objectives & - Subject matter is too boring to learn \\
- Helps students reach key points directly & - Students lose ability of self-reflection and \\
- Has a clear structure and logic & thinking \\
- Guides students to learn and understand more & - Students are unable to focus \\
theories & - It is easy to forget the knowledge \\
& - It is hard to apply theories in the real world \\
\hline
\end{tabular}




\section{Next Phase of Research}

Considering the results of the research reported above, a second phase of research will be introduced in the next part of this paper: Developing principles governing game design for ethics teaching.

Based on the observation of ethics education in China, it is overwhelmingly the case that the lecture is the principal teaching mode used to develop an ethical awareness among students. It is clear that an engaging and innovative technique for teaching ethics would yield welcome results. It certainly seems that the technological approach would be a necessity in our modern, high-tech society.

It is for this reason that a prototype of a computer game is proposed in order to strengthen ethics education in China, and that is the purpose of this study. In order to examine this proposal more closely, the following broad objectives were identified:

- To describe existing design principles in developing a serious game; and

- To define the design approach for developing a serious game for ethics education at the college level.

\section{Research Context}

This paper is based on empirical work conducted by the authors as part of the project "Design and Evaluate Serious Game Application for Teaching Media Courses", funded by the university that the first and third authors serve. The project is a collaboration between developers in a game company and consultants drawn from lecturers at the University of the West of Scotland. The project aims to identify existing empirical evidence associated with the application of computer games in facilitating teaching theoretical courses in the media- and arts-related disciplines, as well as to provide guidelines for designing an appropriate serious game by producing a design framework and comparing this approach to traditional teaching approaches. By collaborating with the students in the researchers' college, the project will produce knowledge about teaching and learning with the aid of serious games. However, more empirically, this project aims to:

- develop a game used to facilitate teaching;

- provide an original contribution to knowledge by proposing and validating a developing framework for serious game environment; and

- identify the effectiveness of the serious game approach and traditional teaching approaches through quantitative experiments.

In order to achieve these aims, a review will be carried out of existing theory as far as design principles and extant theory guiding this field are concerned.

\section{Theoretically Informed Design Approach}

This study is driven and funded by a college-level project and takes into account the learning and teaching experiences of students and teachers on ethics courses, as well as the already identified positive attitude of students towards game-based 
learning. This paper will review the general design principles of developing games for learning, and then aim to construct the design model for constructing instructional games for ethical courses by focusing on dimensionality analysis.

The design-based research approach is used in this study to design serious games applied in theoretical courses in media- and arts-related courses. A review of existing design principles of game-based learning shows that game designers take various elements into account when developing a game for learning. Such elements include behaviorist elements, cognitivist elements, constructivist elements, and combinations of them (Plass, Homer, \& Kinzer, 2015). However, there is currently no consensus on the design principles of games for learning.

The educational design framework for learning in this study is based on pedagogy, game design principles, and engagement in order to design serious games:

- for learning by considering authenticity;

- for learning for pedagogical purposes;

- in terms of its narrative; and

- in terms of learner engagement.

A synthesis of literature on previous design principles has been conducted to produce a new design framework for developing a serious game for an ethics course in the media- and arts-related disciplines and is reported below.

\section{Literature Review}

Four different dimensions (authenticity, pedagogy, narrative, and engagement) were highlighted as seminal to the study and its ultimate aims. Literature was therefore sourced using these dimensions as guides. The discussion of the literature follows below and uses these dimensions as its guiding light.

\subsection{Authenticity}

Game-based learning plays an important role in education and training, and authenticity plays a key role in this learning context. In fact, authenticity is a crucial factor when designing a motivating game or training device (Anthony, Heiser, \& Chandler, 2013). Authenticity is defined as that which is bona fide, real, or actual (Gorman \& Hunt, 2000). Fidelity is often used to describe authenticity. It is important to note that authenticity in games needs to accurately match the learning expectations of learners in the real world, but does not necessarily need to reproduce reality (Gonçalves, Croset, Ney, Balacheff, \& Bosson, 2010).

The authentic learning environment in higher education provides real-world experiences. In games, instructional and game developers set up learning goals, values, and expectations. While playing games, students learn knowledge in a meaningful context from which critical thinking and reflection are cultivated (Kirkwood \& Beavers, 2013).

Researchers subcategorize authenticity in different ways. Herrington and Her- 
rington (2006) proposed that a high-quality authentic environment is the result of a compromise between "cognitive authenticity" and "physical authenticity". Functional authenticity should be counted into the subcategories of authenticity (Anthony et al., 2013). In their work, fidelity is employed instead of authenticity when categorizing the term. Physical fidelity refers to "the look and feel of the environment" (Anthony et al., 2013: p. 123). Functional fidelity is defined as the function or behaviour of the environment and/or its associated components (ibid). They believe that functional fidelity is part of physical fidelity. Cognitive fidelity is "how the learner or player must think when successfully navigating the environment and performing the required learning tasks" (ibid). Researchers investigate the associations between physical fidelity and cognitive fidelity. High fidelity does not always lead to better performance in learning (Scerbo \& Dawson, 2007). It may result in cognitive overload and ineffective training (Clark, 2008; Romiszowski, 1993; Smode, 1971). Therefore, it is necessary to consider human perception and information processing (Scerbo \& Dawson, 2007).

Gonçalves et al. (2010) discuss three subcategories of authenticity: internal authenticity, external authenticity, and didactical authenticity. Internal authenticity refers to the game remains consistent with a logical sequence of real events (ibid). External authenticity is the perceived likeness with real life reference (ibid). Didactical authenticity is related to appropriation (ibid). The learners are looking for their own solutions and can apply them to other situations in order to achieve the effect of drawing inferences from one example.

The literature is clear that, no matter how authenticity is categorized, there are three major principles linked to authenticity: Firstly, the game per se should feature as the physical world, secondly, it should follow the logic of real events, and, thirdly, learners can reach certain levels in terms of cognition.

\subsection{Pedagogy}

Games in computer-based learning can be described as "applications using the characteristics of video and computer games to create engaging and immersive experiences for delivering specified learning goals, outcomes and experiences" (de Freitas, 2006: p. 9). A growing body of research shows that game-based learning adheres to the constructivist learning mode (Gee, 2003; Schrier, 2006; Dickey, 2005; Good \& Robertson, 2004; Dondlinger, 2007). Constructivism seeks to answer the question of how people acquire knowledge and learn (Bada, 2015). The process of learning is not a stimulus-response reaction, but rather an active process in knowledge construction (Bruning, Schraw, Norby, \& Ronning, 2004). Knowledge is developed based on the own experiences and reflections of learners (Bereiter, 1994).

Game-based learning is an active learning experience. While playing games, learners try to accomplish goals by making certain choices, which may lead to certain consequences. They could judge their choices by the degree to which they attained certain outcomes. Based on experiencing the consequences of the 
choices, their knowledge is constructed. In this perspective, the way in which knowledge is constructed in the process of active learning, the process of trial and error is crucial in knowledge construction. Since games for learning are supposed to be designed to simulate real life as a constructivist learning environment, learners could apply this knowledge in their daily lives. Students might be attracted to come back to keep learning if they find this learning useful.

Games developed for pedagogical purposes must obey certain rules, so that learners in the system engage in an artificial conflict, defined by rules, that results in quantifiable outcomes (Salen \& Zimmerman, 2003: p. 300). Oxland (2004) states that computer games need rules, feedback, an interface for the game world, goals, challenges, and a game environment to function effectively. Such games combine possible information technologies to enable gameplay in a virtual environment (Tang, Hanneghan, \& El Rhalibi, 2009). Game-based learning is the integration of serious learning and interactive entertainment into a newly emerging, highly engaging, and exciting teaching and learning approach. Rollings and Adams (2003) declare that the computer game is a subset of a game that deals with an interactive application for entertainment purposes. Therefore, the design principles for game-based learning should comprise two components: pedagogic principles and game design elements.

Pedagogic purposes and game elements both construct the criteria for the design framework of game-based learning. When designing games for learning, game designers borrows certain gaming principles and use them in real-life settings that engage players (Trybus, 2015). Principles of game-based learning cover five aspects:

1) Intrinsic motivation: playing is by and large voluntary and self-driven;

2) Learning through intense enjoyment and "fun";

3) Authenticity: contextualized, goal oriented instead of abstract learning;

4) Self-reliance and autonomy: passions and interests that lead to a will to specialize; and

5) Experiential learning: learning by doing (Perrotta, Featherstone, Aston, \& Houghton, 2013).

The mechanism of game-based learning is fairly intricate. It should follow, at least, simple and binary rules (if/then) or may require more complex decision-making. Game-based learning should also provide clear but challenging goals within a fictional setting of "fantasy", while providing progressively more difficult levels. In addition, it should provide interaction and a high degree of student control, while delivering immediate and constructive feedback. All or these are bonded together by a social element that allows people to share experiences and build relationships.

Based on the roles and mechanisms they identified, the most significant feature of game-based learning is motivational psychological involvement. Players or students who engage with educational materials in a playful and dynamic 
way. While engaging with the games, students are introduced to concepts and are instructed by making decisions (among others) and eventually reach the intended learning outcome. Games based learning is therefore supportive (if done correctly) of the pedagogic requirements of the academic environment.

\subsection{Game Narratives}

Narrative (story-telling) is a powerful tool when applied in the simulation and game-based training arena (Masse, Pounds, Church, Waters, \& Souders, 2015). The narrative framework of game world includes the story world, characters, emotions, narrative interface, and micro-narratives. The narrative arc cultivates players' ability of in-game research and trial and error. The story elements provide certain context for players to take the challenge and solve problems. Three elements of game narrative, 1) the story, 2) the presentation of discourse, which is the game world as presented by the characteristics of game interactivity and nonlinear plot, and 3) interaction with the game world need to be considered. Interaction with the game world generates the story and constructs the knowledge which is supposed to be obtained. In this regard, "what happened" is a crucial experience which is generated from both the pre-scripted parts by game designers and creative parts by game players (Dansky \& Kane, 2006). Thus, the learner becomes an active partner in learning.

\subsubsection{Narrative and Learning}

Both instructional designers and game designers need to ensure a balance between story and instruction. Stories play an important role in human beings' life. Storytelling is a reflective, transformative, and experimental teaching and learning method. It is an effective way to share experiences, pass down history, cultural belief and traditions, and imagine the future (Masse et al., 2015). Storytelling as a teaching pedagogy has been reinforced by a number of grounded learning theories (Masse et al., 2015). Research supported by the U.S. Department of Education proved that students with low motivation and weak academic skills intend to study hard in the context of storytelling. Story embedded into the teaching process results in learners recalling content, developing language (Skala, 2003), learning mathematics (Butterworth \& Lo Cicero, 2001), understanding science concepts (Kukaswadia, 2013), and improving problem-solving skills (Koenig \& Zorn, 2002). Indeed, Egan (1986: p. 459) reminds us that storytelling "encourages us to think of the curriculum as a collection of the greatest stories of our culture".

An effective story benefits the learner in two aspects, 1) it may stimulate learners' learning motivation, and 2) it is generated around the instructional objectives (Masse et al., 2015). Designer-driven and player-driven approaches are often used by game designers to enhance learners' engagement. The two ends of the spectrum are the ways in which the story is designed (game designer) and who controls the action and objectives (the player/learner). In the designer-driven story, game designers are driving the control of that story (ibid). The 
players can control the objectives on the lowest level. On the next level, players need to accomplish the designer-driven goals. The highest level explains the motivation of the actors. All the stories involved in this type of story are driven by the designer. However, the player-driven approach basically depends on the exploration of players from which players can achieve their own goals (ibid).

Each course, based on the syllabus, comprises a vital part called intended learning outcome (ILO). Learning outcomes (LOs) are the implementation tools for objectives (Greensted \& Hommel, 2014). LOs describe what students are able to demonstrate or do upon completion of a unit of study, the course, and the program as a whole. ILOs offered in universities are pre-set by academic committees and field experts. Students are supposed to achieve all of the course intended learning outcomes. They do not have much free space to establish their own learning objectives. Notwithstanding a lack of such space, serious games support learning the effect because of the goal-driven characteristics and realistic environment (Qin, 2009). In this sense, the designer-driven approach matches the pedagogical purposes in teaching courses in higher education. Instructional designers and game designers need to work together and integrate game elements and pedagogical purposes.

\subsubsection{Adding Value}

Technology has always been deemed as an immensely powerful force for change in society. It is effective, innovative, and efficient. Technology not only facilitates life and work, but also promotes the values of society and culture. Computer games, as a special kind of technology, function as a promotional tool to spread social and cultural values. Flanagan and Nissenbaum (2007) articulated a game design methodology called Values at Play (VAP). The preliminary idea is that ethical ideals or human values should be embedded in game design. These values include liberty, justice, inclusion, equality, privacy, security, creativity, trust, and personal autonomy (ibid). In the creation of games and the teaching of game design, creating socially conscious games can be applied to the design of educational games (ibid). The values addressed in Flanagan and Nissenbaum's work coincides with the main topics of the course Applied Ethics in Media and Cultural industries. Therefore, it could be considered as one of the design aspects in developing games for the ethical course.

\subsection{Game Engagement}

One of the potentially pedagogically powerful aspects of game-based learning is its ability to engage learners actively in the process of learning. Game engagement particularly serves to motivate and immerse learners in the learning process.

\subsubsection{Motivation}

Notwithstanding the fact that games in nature are more like a form of entertainment, evidence shows that motivation and engagement are strongly corre- 
lated with learning in game-based techniques (Gee, 2007; Prensky, 2005; Squire, 2011; Rowe, Shores, Mott, \& Lester, 2011). One of the most frequently cited reasons to consider games for learning is that games can affect students learning motivation and engagement (Sabourin \& Lester, 2014). A growing body of research shows that interest is one of the critical factors influencing students' engagement with educational software (Muldner, Burleson, Sand, \& Vanlehn, 2010; Baker, Corbett, Koedinger, \& Wagner, 2004; Beal, Qu, \& Lee, 2006). That is because the mechanics in games encompassing rules, clear objectives, assessable goals, as well as cooperation and competition encourage an interactive experience which further generate a sense of achievement. Learners are often motivated by the hands-on learning opportunities which may pull them back to learn more. Kapp (2012) argues that, because of its game-like features and environments, educational games positively influence learners' affect, engagement, and motivation. In this regard, the subjective experiences of players are the core reasons explaining engagement in games (Kiili, de Freitas, Arnab, \& Lainema, 2012).

\subsubsection{Immersion}

The majority of research regarding games accounts for the following topics: flow, immersion, presence, and cognitive absorption (Agarwal \& Karahanna, 2000; Brown \& Cairns, 2004; McMahan, 2003; Witmer \& Singer, 1998). A widely used term, immersion, is a crucial element in consideration of game enjoyment (Brown \& Cairns, 2004; Nacke \& Lindley, 2008; Jennett, Cox, Cairns, Dhoparee, Epps, Tijs, \& Walton, 2008; Jennett, Cox \& Cairns, 2009; Hooi \& Cho, 2012). Immersion can be defined as "the sensation of being surrounded by a completely other reality $[\ldots]$ that takes over all of our attention, our whole perceptual apparatus" (Murray, 1997: p. 98).

Computer games provide immersive sense for players (Nordin, Ali, Animashaun, Asch, Adams, \& Cairns, 2013; Brown \& Cairns, 2004; Thompson, Nordin, \& Cairns, 2012). Playing games result in lack of awareness of the real world (Sweetser \& Wyeth, 2005; Jennett et al., 2008; Qin, Rau, \& Salvendy, 2010; Hooi \& Cho, 2012). Because of the rigid rules, specific goals, and difficult levels, the player is immersed while interacting with the game. Sweetser and Wyeth (2005) found that the player feels totally immersed in a game when they encounter a task with clear goals and has a proper difficulty level. Other factors influencing the feeling of immersion are the pace of a game (Qin et al., 2010), the use of narrative (Gerling, Birk, Regan, \& Doucette, 2013), high-fidelity graphics (Gerling et al., 2013), challenge and curiosity (Qin, Rau, \& Salvendy, 2009), the balance between the players' skill, and challenge in the game (Nacke \& Lindley, 2008). In this sense, the sense of being in the game is widely related to a wide variety of factors. Moreover, immersion clearly connotes the mental processes while playing games (Ermi \& Mayra, 2005). Therefore, those factors work as the referential point for game designers to develop an immersive game for learners. 


\section{Proposed Design Model}

Based on the above reviewed design principles and elements, the research team proposed a model that combined pedagogy as well as other identified game design principles, which is reflected in Figure 1 on the next page. The preliminary goal is to establish an educational game design model for teaching ethical courses. The model combines four dimensions: authenticity, pedagogy, game narratives, and game engagement. Under authenticity, physical fidelity and cognitive fidelity will be the focus. Both dimensions are important in designing game for learning. Through the special virtual learning environment, the cognitive effect is enhanced. As for the pedagogical dimension, the focal point is on the degree to which the game will achieve the intended learning outcomes. For this objective, the game will be designed based on selected themes covered in the course of "Applied Ethics". Upon completion of the gameplay, students will be simultaneously obtaining the assessments in which assess their learning effect.

This model, as a supplementary teaching and learning approach, is designed both for self-learning and traditional lecture-based teaching. Therefore, a computer game will be used either during lecture time or after class activity. Game narrative will be the reference point for game designers to design non-linear plot and adding social and cultural value into the games. The fourth dimension, game engagement, is to be applied to evaluate the students' motivation and immersion compared to traditional lecture-based lessons.

\section{Conclusion}

Scholars have proposed varied game design models and developed several real educational games for pedagogical purposes. Their attractiveness and positive effects have been proved by a number of empirical research projects. The model proposed in this paper intends to add more knowledge to ethics course games design. It calls for future investigation of the improvement in game-based learning in ethics. These game design principles for ethics education will be developed based on the proposed model. The subsequent experiment will test:

1) the differences between the traditional lecture-based teaching approach and game-based learning;

2) the degree of students' motivation and engagement; and

3) the effectiveness of obtaining knowledge matching the intended learning outcomes.

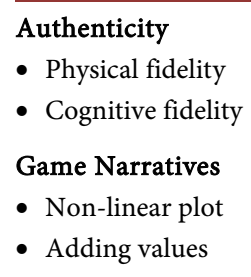

- Non-linear plot

- Adding values

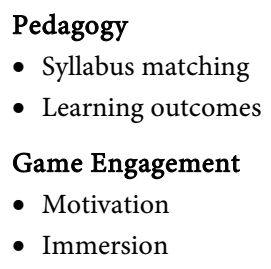

Figure 1. Game design model for teaching ethics. 
The on-going research will provide some insight into games design for teaching and learning ethics and, in doing so, contribute to the improvement of social morality.

\section{Conflicts of Interest}

The authors declare no conflicts of interest regarding the publication of this paper.

\section{References}

Agarwal, R., \& Karahanna, E. (2000). Time Flies When You're Having Fun: Cognitive Absorption and Beliefs about Information Technology Usage. MIS Quarterly, 24, 665-694. https://doi.org/10.2307/3250951

Anthony, M., Heiser, E., \& Chandler, T. (2013). Authenticity in Learning Games. In T. S. Hussain, \& S. L. Coleman (Eds.), Design and Development of Training Games: Practical guidelines from a Multidisciplinary Perspective (pp. 121-145). Cambridge: Cambridge University Press. https://doi.org/10.1017/CBO9781107280137.006

Bada, S. O. (2015). Constructivism Learning Theory: A Paradigm for Teaching and Learning. Journal of Research \& Method in Education, 5, 66-70.

Baker, R. S., Corbett, A. T., Koedinger, K. R., \& Wagner, A. (2004). Off Task Behavior in the Cognitive Tutor Classroom: When Students Game the System. In Proceedings of SIGCHI Conference Human Factors in Computing Systems (pp. 383-390). New York: ACM. https://doi.org/10.1145/985692.985741

Beal, C. R., Qu, L., \& Lee, H. (2006). Classifying Learner Engagement through Integration of Multiple Data Sources. In Proceedings of Conference Artificial Intelligence (pp. 151-156). Menlo Park, CA: AAAI Press.

Bereiter, C. (1994). Constructivism, Socioculturalism, and Popper's World 3. Educational Researcher, 23, 21-23. https://doi.org/10.3102/0013189X023007021

Brown, E., \& Cairns, P. (2004). A Grounded Investigation of Game Immersion. In CHI 2004, ACM Conference on Human Factors in Computing (pp. 1297-1300). New York: ACM Press. https://doi.org/10.1145/985921.986048

Bruning, R., Schraw, G., Norby, M., \& Ronning, R. (2004). Cognitive Psychology and Instruction. Upper Saddle River, NJ: Prentice Hall.

Butterworth, S., \& Lo Cicero, A. M. (2001). Storytelling: Building a Mathematics Curriculum from the Culture of the Child. Teaching Children Mathematics, 7, 396-399.

Clark, R. D. (2008). Building Expertise: Cognitive Methods for Training and Performance Improvement (A Publication of the International Society for Performance Improvement). San Francisco, CA: Pfeiffer.

Dansky, R., \& Kane, B. (2006). Book Excerpt and Review-Game Writing: Narrative Skills for Videogames.

https://www.gamasutra.com/view/feature/130255/book_excerpt_and_review_game_. php?page $=15$

De Freitas, S. (2006). Learning in Immersive Worlds. London: Joint Information Systems Committee.

Dickey, M. D. (2005). Engaging by Design: How Engagement Strategies in Popular Computer and Video Games Can Inform Instructional Design. Educational Technology Research and Development, 53, 67-83. https://doi.org/10.1007/BF02504866

Dinc, L., \& Görgülü, R. S. (2002). Teaching Ethics in Nursing. Nursing Ethics, 9, 259-268. 
https://doi.org/10.1177/096973300200900305

Dondlinger, M. J. (2007). Educational Video Game Design: A Review of the Literature. Journal of Applied Educational Technology, 4, 21-31.

Egan, K. (1986). Teaching as Story Telling: An Alternative Approach to Teaching and Curriculum in the Elementary School. Chicago: University of Chicago Press.

Ermi, L., \& Mayra, F. (2005). Fundamental Components of the Gameplay Experience: Analyzing Immersion. In S. Castell, \& J. Jenson (Eds.), Changing Views: Worlds in Play, Selected Papers of the 2005 Digital Games Research Association's Second International Conference (pp. 15-27). Vancouver: Digital Games Research Association \& Simon Fraser University.

Flanagan, M., \& Nissenbaum, H. (2007). A Game Design Methodology to Incorporate Social Activist Themes. In Proceedings of the SIGCHI Conference on Human Factors in Computing Systems (pp. 181-190). New York: ACM. https://doi.org/10.1145/1240624.1240654

Gee, J. P. (2007). Good Video Games and Good Learning: Collected Essays on Video Games, Learning and Literacy (2nd ed.). New York: P. Lang.

https://doi.org/10.3726/978-1-4539-1162-4

Gee. J. P. (2003). What Video Games Have to Teach Us about Learning and Literacy. New York: Palgrave Macmillan. https://doi.org/10.1145/950566.950595

Gerling, K. M., Birk, M. M., Regan, L., \& Doucette, A. (2013) The Effects of Graphical Fidelity on Player Experience. In Proceedings of International Conference on Making Sense of Converging Media (p. 229). New York: ACM.

https://doi.org/10.1145/2523429.2523473

Gonçalves, C., Croset, M. C., Ney, M., Balacheff, N., \& Bosson, J. L. (2010) Authenticity in Learning Game: How It Is Designed and Perceived. In M. Wolpers, P. A. Kirschner, M. Scheffel, S. Lindstaedt, \& V. Dimitrova (Eds.), Sustaining TEL: From Innovation to Learning and Practice (pp. 109-122). Berlin: Springer.

https://doi.org/10.1007/978-3-642-16020-2_8

Good, J., \& Robertson, J. (2004). Computer Games Authored by Children: A Multi-Perspective Evaluation. In Proceedings of the 2004 Conference on Interaction Design and Children: Building a Community (pp. 123-124). New York: ACM. https://doi.org/10.1145/1017833.1017852

Gorman \& Hunt (2000). 19 S.W.3d $662(\mathrm{Ky})$.

Greensted, C., \& Hommel, U. (2014). Intended Learning Outcomes-Friend or Foe? EFMD Global Focus, 8, 20-25.

Gropelli, T. M. (2010). Using Active Simulation to Enhance Learning of Nursing Ethics. The Journal of Continuing Education in Nursing, 41, 104-105. https://doi.org/10.3928/00220124-20100224-09

Herrington, T., \& Herrington, J. (2006). Authentic Learning Environments in Higher Education. Hershey, PA: Information Science Publishing. https://doi.org/10.4018/978-1-59140-594-8

Hooi, R., \& Cho, H. (2012). Being Immersed: Avatar Similarity and Self-Awareness. In Proceedings of the 24th Australian Computer-Human Interaction Conference (pp. 232-240). New York: ACM. https://doi.org/10.1145/2414536.2414576

Jennett, C., Cox, A. L., \& Cairns, P. (2009). Investigating Computer Game Immersion and the Component Real World Dissociation. In CHI'09 Extended Abstracts on Human Factors in Computing Systems (pp. 3407-3412). New York: ACM.

https://doi.org/10.1145/1520340.1520494 
Jennett, C., Cox, A. L., Cairns, P., Dhoparee, S., Epps, A., Tijs, T., \& Walton, A. (2008). Measuring and Defining the Experience of Immersion in Games. International Journal of Human-Computer Studies, 66, 641-661. https://doi.org/10.1016/j.ijhcs.2008.04.004

Kalaitzidis, E., \& Schmitz, K. (2012). A Study of an Ethics Education Topic for Undergraduate Nursing Students. Nurse Education Today, 32, 111-115. https://doi.org/10.1016/j.nedt.2011.02.006

Kapp, K. (2012). The Gamification of Learning and Instruction: Game-Based Methods and Strategies for Training and Education. San Francisco, CA: Pfeiffer. https://doi.org/10.1145/2207270.2211316

Kiili, K., de Freitas, S., Arnab, S., \& Lainema, T. (2012). The Design Principles for Flow Experience in Educational Games. Procedia Computer Science, 15, 78-91. https://doi.org/10.1016/j.procs.2012.10.060

Kirkwood, D., \& Beavers, E. (2013). Create an Authentic, Inclusive Early Childhood Learning Environment for Teacher Candidates. Dimensions of Early Childhood, 41, 3-9

Koenig, J., \& Zorn, C. (2002). Using Storytelling as an Approach to Teaching and Learning with Diverse Students. Journal of Nursing Education, 41, 393-399.

Kukaswadia, A. (2013). Science and Storytelling: The Use of Stories in Science Education. https://blogs.plos.org/scied/2013/06/24/science-and-storytelling-the-use-of-stories-in-s cience-education

Martinkovičová, M., \& Benčiková, D. (2017). The Ethical Competence of Graduates as Part of Their Professional Competence. Scientific Papers of Silesian University of Technology: Organization and Management, No. 110, 139-150.

https://doi.org/10.29119/1641-3466.2017.110.13

Masse, C. Pounds, K., Church, E., Waters, R. E., \& Souders, V. (2015). Story for Learning and Gaming. In T. S. Hussain, \& S. L. Coleman (Eds.), Design and Development of Training Games: Practical Guidelines from a Multidisciplinary Perspective (pp. 93-120). Cambridge: Cambridge University Press. https://doi.org/10.1017/CBO9781107280137.005

McMahan, A. (2003). Immersion, Engagement, and Presence: A Method for Analyzing 3-D Video Games. In M. J. P. Wolf, \& B. Perron (Eds.), The Video Game Theory Reader (pp. 67-86). Abingdon-on-Thames: Routledge, Taylor \& Francis Group.

Muldner, K., Burleson, W., Van de Sand, B., \& VanLehn, K. (2010). An Analysis of Gaming Behaviors in an Intelligent Tutoring System. In V. Aleven, J. Kay, \& J. Mostow (Eds.), Intelligent Tutoring Systems (pp. 184-193). Lecture Notes in Computer Science, Vol. 6094, Heidelberg: Springer. https://doi.org/10.1007/978-3-642-13388-6_23

Murray, J. H. (1997). Hamlet on the Holodeck: The Future of Narrative in Cyberspace. Cambridge, MA: The MIT Press.

Nacke, L., \& Lindley, C. A. (2008). Flow and Immersion in First-Person Shooters: Measuring the Player's Gameplay Experience. In Proceedings of the 2008 Conference on Future Play: Research, Play, Share (pp. 81-88). New York: ACM.

https://doi.org/10.1145/1496984.1496998

Nordin, A. I., Ali, J., Animashaun, A., Asch, J., Adams, J., \& Cairins, P. (2013). Attention, Time Perception and Immersion in Games. In Progress CHI 2013 Changing Perspectives on Human Factors in Computing Systems (pp. 1089-1094). New York: ACM. https://doi.org/10.1145/2468356.2468551

Oxland, K. (2004). Gameplay and Design. Boston, MA: Addison Wesley.

Perrotta, C., Featherstone, G., Aston, H., \& Houghton, E. (2013). Game-Based Learning: 
Latest Evidence and Future Directions. Slough: NFER.

Plass, J. L., Homer, B. D., \& Kinzer, C. K. (2015). Foundations of Game-Based Learning. Educational Psychologist, 50, 258-283. https://doi.org/10.1080/00461520.2015.1122533

Prensky, M. (2005). Computer Games and Learning: Digital Game-Based Learning. In J. Raessens, \& J. Goldstein (Eds.), Handbook of Computer Game Studies (Vol. 18, pp. 97-122). Cambridge, MA: MIT Press.

Qin, H. (2009). Study on Player Immersion and Difficulty in the Computer Game Narrative. Doctoral Thesis, Beijing: Tsinghua University. https://doi.org/10.1080/10447310802546732

Qin, H., Rau, P. L. P., \& Salvendy, G. (2009). Measuring Player Immersion in the Computer Game Narrative. International Journal of Human-Computer Interaction, 25, 107-133. https://doi.org/10.1080/10447310802546732

Qin, H., Rau, P. L. P., \& Salvendy, G. (2010). Effects of Different Scenarios of Game Difficulty on Player Immersion. Interacting with Computers, 22, 230-239.

https://doi.org/10.1016/j.intcom.2009.12.004

Rollings, A., \& Adams, E. (2003). Andrew Rolling and Ernest Adams on Game Design. New Riders.

Romiszowski, A. J. (1993). Psychomotor Principles. In M. Fleming, \& W. H. Levie (Eds.), Instructional Message Design: Principles from the Behavioral and Cognitive Sciences (2nd ed.). Englewood Cliffs, NJ: Educational Technology Pubns.

Rowe, J. P., Shores, L. R., Mott, B. W., \& Lester, J. C. (2011). Integrating Learning, Problem Solving, and Engagement in Narrative-Centered Learning Environments. International Journal of Artificial Intelligence in Education, 21, 115-133.

Sabourin, J. L., \& Lester, J. C. (2014). Affect and Engagement in Game-Based Learning Environments. IEEE Transactions on Affective Computing, 5, 45-56.

https://doi.org/10.1109/T-AFFC.2013.27

Salen, K., \& Zimmerman, E. (2003). Rules of Play: Game Design Fundamentals. Cambridge, MA: The MIT Press.

Scerbo, M. W., \& Dawson, S. (2007). High Fidelity, High Performance? Simulation in Healthcare, 2, 224-230. https://doi.org/10.1097/SIH.0b013e31815c25f1

Schrier, K. (2006). Using Augmented Reality Games to Teach 21st Century Skills. In ACM SIGGRAPH 2006 Educators Program (p. 15). New York: ACM. https://doi.org/10.1145/1179295.1179311

Shang, D., Liu, G., \& Cao, S. (2019). Why Are Chinese Ethics Declining? Time \& Society, 28, 438-453. https://doi.org/10.1177/0961463X16658803

Skala, C. (2003). Optimizing Basic French Skills Utilizing Multiple Teaching Techniques (p. 31). ERIC Accession No. 479988, Unpublished Master's Thesis, Chicago, IL: St. Xavier University.

Smode, A. F. (1971). Human Factors Inputs to the Training Device Design Process.

Squire, K. (2011). Video Games and Learning: Teaching and Participatory Culture in the Digital Age. Technology, Education-Connections (The TEC Series), New York: Teachers College Press.

Sweetser, P., \& Wyeth, P. (2005). GameFlow: A Model for Evaluating Player Enjoyment in Games. Computers in Entertainment (CIE), 3, 1-24.

https://doi.org/10.1145/1077246.1077253

Tang, S., Hanneghan, M., \& El Rhalibi, A. (2009). Introduction to Game-Based Learning. In Games Based Learning Advancements for Multi-Sensory Human Computer Inter- 
faces (pp. 1-17). New York: IGI Global.

https://doi.org/10.4018/978-1-60566-360-9.ch001

Thompson, M., Nordin, I., \& Cairns, P. (2012). Effect of Touch-Screen Size on Game Immersion. In Proceedings of the 26th Annual BCS Interaction Specialist Group Conference on People and Computers (pp. 280-285). Swindon: BCS Learning \& Development Ltd.

Trybus, J. (2015). Game-Based Learning: What It Is, Why It Works, and Where It's Going. Miami: New Media Institute.

http://www.newmedia.org/game-based-learning--what-it-is-why-it-works-and-where-i ts-going.html

Tuxbury, J. S., McCauley, P. M., \& Lement, W. (2012). Wall McCauley PM and Lement W. Nursing and Theatre Collaborate: An End-of-Life Simulation Using Forum Theatre. Journal of Nursing Education, 51, 462-465.

https://doi.org/10.3928/01484834-20120615-02

Vanlaere, L., Coucke, T., \& Gastmans, C. (2010). Experiential Learning of Empathy in a Care-Ethics Lab. Nursing Ethics, 17, 325-336.

https://doi.org/10.1177/0969733010361440

Witmer, B. G., \& Singer, M. J. (1998). Measuring Presence in Virtual Environments: A Presence Questionnaire. Presence, Teleoperators and Virtual Environments, 7, 225-240. https://doi.org/10.1162/105474698565686 